\title{
Breakup Distress and Loss of Intimacy in University Students
}

\author{
Tiffany Field $^{1,2}$, Miguel Diego ${ }^{1}$, Martha Pelaez ${ }^{3}$, Osvelia Deeds ${ }^{3}$, Jeannette Delgado ${ }^{1}$ \\ ${ }^{1}$ Department of Pediatrics, University of Miami Medical School, Miami, USA; ${ }^{2}$ Fielding Graduate University, Santa Barbara, USA; \\ ${ }^{3}$ Department of Psychology, Florida International University, Miami, USA. \\ Email: tfield@med.miami.edu
}

Received May 26 ${ }^{\text {th }}, 2010$; revised July $3^{\text {rd }}, 2010$; accepted July $6^{\text {th }}, 2010$.

\begin{abstract}
Breakup distress and reasons for breakup including affiliation, intimacy, sexuality and autonomy reasons were studied in 119 university students who had experienced a recent breakup of a romantic relationship. The sample was divided into high and low breakup distress groups based on a median score on the Breakup Distress Scale. The groups were then compared on their responses on the Breakup Reasons Scale. Only the intimacy subscale differentiated the high versus low breakup distress groups. These data highlight the importance of intimacy for romantic relationships and the loss of intimacy as a reason for breakups.
\end{abstract}

Keywords: Intimacy, University Students, Breakup Distress

\section{Introduction}

Breakup distress in university students has been related to several factors. Breakup distress has been greater for those who attributed the breakup to the other person (e.g. the partner's mood or insensitivity) or to environmental factors (e.g. work stress or friends being disruptive to the relationship) [1]. Breakup distress in university students has also been related to global negative beliefs about the self and cognitions reflecting self-blame [2].

In a study we conducted, university students who had high Breakup Distress Scale sores reported: 1) not initiating the breakup; 2) that the breakup was sudden and unexpected; 3) that they felt rejected and betrayed; 4) that they had less time since the breakup occurred; and 5) that they had not yet found a new relationship [3]. In this study, university students who had experienced a recent breakup of a romantic relationship were divided into high versus low score groups based on the Breakup Distress Scale. Females had higher Breakup Distress Scale scores. Students with high breakup distress scores also scored higher on the Intrusive Thoughts Scale, the Difficulty Controlling Intrusive Thoughts Scale, the Sleep Disturbances Scale and on depression and anxiety scales. In a regression analysis, the most important predictors of the breakup distress scores were depression, feeling betrayed by the breakup, shorter time since the breakup occurred and a higher rating of the relationship prior to the breakup. This explained as much as $37 \%$ of the variance, suggesting that these factors are important contributors to relationship breakup distress, but also suggesting that a large part of the outcome variance was not yet explained. In another study on college students, the closeness and the duration of the broken relationship predicted the intensity and the duration of emotional distress following the breakup [4]. At least one other investigator reported that greater levels of love were associated with a decreased probability of recovering from the breakup [5].

Fewer studies have been conducted on the reasons for romantic breakups. In a longitudinal study, the primary reason for breakup among college students was unequal involvement in the relationship [6]. This phenomenon may be similar to the "romantic disengagement" preceding breakups reported by others [7]. In that study, romantic disengagement, in turn, was negatively related to intimacy, suggesting the breakdown of intimacy as a reason for breakups.

The reasons for breakups and how they relate to breakup distress were the primary focus of the current study. One might argue that the reasons for breakup may be the loss of important qualities of the relationship. Collins [8] suggested that romantic relationships provide a context for the maturation of intimacy, affiliation, sexuality and autonomy. Breakups are also related to these factors [9]. As these authors noted, "the initiation of a romantic relationship in adolescence is propelled by the combination of a young person's emerging need for sexuality with a 
heightened need for intimacy with non-familiar others” [9]. The intimacy needs involve emotional closeness with a partner including having trust, understanding, disclosure and the mutual expression of loving feelings. The need for affiliation is thought to include companionship, spending time together and sharing activities. And, the sexuality needs are thought to include sexual attraction and physical affection. Some have suggested that there is an age-related decrease in the focus on affiliative and sexual dimensions of relationships with a greater focus on intimacy [10].

In a study on breakup reasons, high school students were asked to provide a written response to the question "What was the most important reason why your last romantic relationship ended?” [9]. The adolescents' explanations for the breakups were then reviewed and coded using a categorical-content qualitative analysis method [11]. The authors suggested that since the responses were brief, they were assigned a code for the hypothesized content-categories of intimacy, affiliation, sexuality, identity and autonomy. The affiliation category included breakup reasons like no time together, boredom, and disinterest while the intimacy category included items like absence of love, distrust/dishonesty, poor communication and poor treatment. Sexuality items included sexual dissatisfaction and lack of physical attraction. The authors found that problems with affiliation (44\%) and intimacy (36\%) were more prevalent in adolescents' breakup accounts than were problems with sexuality (20\%). One of the problems of this study, as was acknowledged by its authors, was that the students were only being asked to give the most important reason for the breakup when in fact the breakup may have occurred for many reasons, some big, some small. In addition, the qualitative method limits the power of the data analysis. Nonetheless, the data are highly suggestive and were used as the foundation for the current study.

In the present study, a Breakup Reasons Scale was created from many of the items from the Connelly and McIsaac [9] study and was administered to university students. In addition, to determine how breakup reasons vary by breakup distress, the Breakup Distress Scale was administered, and the sample was divided into high and low distress groups based on a median split on that scale. The groups were then compared on the Breakup Reasons scale total score and the subscale scores labeled affiliation, intimacy, sexuality and autonomy. Other ratings were also completed as potential confounding variables including ratings on the relationship, the partner and the ideal relationship.

\section{Methods}

\subsection{Participants}

The initial sample was 156 students $(\mathrm{N}=112$ females) who were recruited at a southeastern university. Of this sample, 119 (76\%) had experienced a breakup 3.5 months ago on average after a relationship that averaged 3.3 months duration. The students had experienced 2.9 breakups on average, 2.0 of them having been with the same partner. The breakup sample was divided into high and low breakup distress groups based on a median split on the Breakup Distress Scale. No differences were noted between the two groups on demographic variables (ethnicity, age, and grade) except for gender. For the high and low distress groups respectively: 1) age averaged 24.2 and 24.4; 2) grade averaged 13.6 and 13.3; and 3) ethnicity was distributed Hispanic (75\% and 80\%), Caucasian (9\% and 13\%), African-American (6\% and $2 \%$ ) and other (10\% and $5 \%)$ (all ps non-significant). The high Breakup Distress Scale score group had more females than the low distress group ( $86 \%$ vs. $68 \%, \underline{X}^{2}=$ 5.67, $\mathrm{p}<.02$ ), and females had higher scores on the Breakup Distress Scale ( $\mathrm{M}=10.2$ vs. 7.1, $\mathrm{F}=6.41, \mathrm{p}$ $=.01)$.

\subsection{Procedures}

The students were recruited for this anonymous questionnaire study from psychology classes and given extra credit for their participation. During one of their class sessions, the students completed a questionnaire that was comprised of demographic questions, the Breakup Distress Scale, the Breakup Reasons Scale, and ratings on their relationship before the breakup, how much they missed their partner and what they viewed as the ideal relationship.

\subsection{Measures}

The Breakup Distress Scale (BDS) [3] was adapted from the Inventory of Complicated Grief (ICG) [12]. Based on that study, the internal consistency of the 19-item ICG was high (Cronbach's $\alpha=0.94$ ).

The Breakup Distress Scale was adapted from the ICG by referring to the breakup person instead of the deceased person, and only 16 of the 19 ICG items that were appropriate to breakups were included. A different rating scale was also used, i.e. a Likert scale with responses ranging from 1 (not at all) to 4 (very much so) including: 1) I think about this person so much that it's hard for me to do things I normally do; 2) Memories of the person upset me; 3) I feel I cannot accept the breakup I've experienced; 4) I feel drawn to places and things associated with the person; 5) I can't help feeling angry about the breakup; 6) I feel distressed about what happened; 7) I feel stunned or dazed over what happened; 8) Ever since the breakup it is hard for me to trust people; 9) Ever since the breakup I feel like I have lost the ability to care about other people or I feel distant from people I care about; 10) I have been experiencing pain since the breakup; 11) I go out of my way to avoid reminders of the 
person; 12) I feel that life is empty without the person; 13) I feel bitter over this breakup; 14) I feel envious of others who have not experienced a breakup like this; 15) I feel lonely a great deal of the time since the breakup; and 16) I feel like crying when I think about the person. The internal consistency of this 16-item scale was also high (alpha $=.91)$.

Other ratings were used to address relationship variables that might confound the breakup distress experience. These included rating the relationship as it was before the breakup, rating what the student missed about the partner, and the student's view of an ideal relationship.

The Breakup Reasons Scale (BRS) is a 20-item scale that was developed for this study based on the qualitative study done on high school students' explanations for their romantic breakups [9]. As already mentioned, they identified five categories of breakup reasons including intimacy, affiliation, sexuality, autonomy and identity. The scale used in this study included subscales on 8 intimacy items, 7 affiliation items, 3 sexuality items and 2 autonomy items. Each of these items was rated on a 4-point Likert scale. These items appear in Table 1. The internal consistency for this 20-item scale was high (alpha $=.93$ ). The alphas for the subscales were moderate to high (intimacy $=.84$, affiliation $=.79$, sexuality $=.71$; autonomy $=.67$ ).

The Relationship ratings included 5 items rated on a 4 point Likert scale including rating of the relationship from 1 (ok) to 4 (wonderful).The other items were rated from 1 (not at all) to 4 (very much so) including: 1 ) did you and your partner share a lot of activities/interests together? 2) did you and your partner share a lot of your thoughts and feelings together? 3) did you and your partner show a lot of affection toward each other? and 4) did and your partner have a lot of disagreements? (reverse scored). These were then totaled for a summary rating.

The Missing the Partner ratings were also made on a Likert scale from 1 (totally disagree) to 4 (totally agree). The items read, after the breakup: 1) I missed our daily activities/rhythms; 2) I missed our talking/emotional closeness; and 3) I missed our touching/physical closeness. These were added for a total rating.

The Ideal Relationship ratings were also made on a Likert rating scale from 1 (almost never) to 4 (almost always). The 11 items included "behaviors that you look for in an ideal relationship” including: 1) Sharing favorite activities; 2) A reciprocal relationship that is fair and balanced; 3) A calming influence; 4) Nurturing behavior;

Table 1. Mean subscale and total scores on the Breakup Reasons Scale (standard deviations in parentheses) for low and high distress groups and items of each subscale

\begin{tabular}{|c|c|c|c|c|}
\hline & \multicolumn{4}{|c|}{ Groups } \\
\hline & Low Distress & High Distress & $\mathrm{F}$ & $\mathrm{p}$ \\
\hline Intimacy & $15.70(6.18)$ & $20.04(5.73)$ & 14.41 & .000 \\
\hline Distrust & $2.13(1.14)$ & $2.85(1.24)$ & & \\
\hline Unreciprocated love & $1.70(0.88)$ & $2.42(1.18)$ & & \\
\hline Non-caring behavior & 1.85 (0.99) & $2.50(1.14)$ & & \\
\hline Diminishing empathy & $1.82(1.16)$ & $2.22(1.05)$ & & \\
\hline Arguments & $2.27(1.16)$ & $2.71(1.25)$ & & \\
\hline Infidelity & $1.82(1.16)$ & $2.24(1.05)$ & & \\
\hline Hypersensitivity & $1.76(0.94)$ & $2.24(1.05)$ & & \\
\hline Affiliation & $14.28(5.47)$ & $14.81(5.49)$ & & NS \\
\hline Boredom & $2.16(1.10)$ & $2.08(1.16)$ & & \\
\hline Lack of time together & $1.98(1.16)$ & $2.32(1.14)$ & & \\
\hline Dissimilar traits & $1.96(1.14)$ & $2.17(1.18)$ & & \\
\hline Diminishing fun & $2.13(1.10)$ & $2.16(1.09)$ & & \\
\hline Diminishing excitement. & $2.20(1.13)$ & $2.17(1.07)$ & & \\
\hline Increasing time during other activities & $1.93(1.09)$ & $2.14(1.05)$ & & \\
\hline Sexuality & $5.71(2.79)$ & $6.00(2.76)$ & & NS \\
\hline Sexual dissatisfactions & $1.82(1.09)$ & $2.15(1.16)$ & & \\
\hline Diminishing physical attraction & $1.96(1.14)$ & $1.88(1.04)$ & & \\
\hline Diminishing physical affection & $1.93(1.05)$ & $1.97(1.08)$ & & \\
\hline Autonomy & $3.96(1.90)$ & $4.46(1.98)$ & & NS \\
\hline Problem maintaining independent self & $1.89(1.04)$ & $2.19(1.17)$ & & \\
\hline Control & $2.07(1.18)$ & $2.27(1.22)$ & & \\
\hline Total score & $17.28(12.79)$ & $23.75(11.97)$ & 7.71 & .006 \\
\hline
\end{tabular}


5) Allowing for my independence/room to breathe; 6) Interesting conversations; 7) Exciting experiences; 8) Humorous/fun-loving; 9) Positive/upbeat; 10) Sexually satisfying and 11) Physically attractive. These were then totaled for a summary rating.

\section{Results}

ANOVAs were conducted on the Breakup Reasons subscales. As can be seen in Table 1, the total score for the intimacy subscale significantly differentiated the high distress from the low distress groups. This subscale included poor communication, distress, unreciprocated love, non-caring behavior, diminishing sympathy, arguments, infidelity and hypersensitivity. Although no group differences were noted on the affiliation, sexuality and autonomy subscales, the total score for the Breakup Reasons Scale was also higher for the high distress group. A correlation analysis suggested the following significant relationships between the subscales and the total Breakup Reasons Scale score: 1 ) intimacy $=.79 ; 2$ ) affiliation $=.66$; 3 ) sexuality $=.53$; and 4 ) autonomy $=.61$ (all ps $<.05)$.

As can be seen in Table 2, ANOVAs on the other ratings on potentially confounding variables yielded significant differences between groups including $\mathrm{n}$ : 1 ) the Relationship Ratings on the relationship prior to the breakup; and 2) Missing the Partner Ratings. The groups did not differ on the Ideal Relationship Rating.

\section{Discussion}

The primary finding that decreasing intimacy was a factor in high breakup distress is perhaps not surprising given that intimacy was a primary reason for breakups in at least one other sample [9]. In that study, $36 \%$ of the adolescents' responses were coded as intimacy-related, and romantic intimacy was defined in terms of establishing a high degree of emotional closeness with a partner, supported by such processes as trust, understanding, disclosure and the mutual expression of loving feelings. Others have described intimacy similarly [13,14]. And, others have referred to the lack of intimacy as disengagement and have reported that disengagement contri-

Table 2. Mean ratings on other variables differentiating the low and high breakup distress groups (standard deviations in parentheses)

\begin{tabular}{|c|c|c|c|c|}
\hline \multicolumn{5}{|c|}{ Groups } \\
\hline Variable & Low Distress & High Distress & $\mathrm{F}$ & $\mathrm{p}$ \\
\hline $\begin{array}{l}\text { Relationships } \\
\text { Rating }\end{array}$ & 7.91 (3.34) & $9.61(3.00)$ & 10.21 & .002 \\
\hline $\begin{array}{l}\text { Missing the } \\
\text { Partner }\end{array}$ & $3.27(2.72)$ & $5.71(2.72)$ & 22.88 & .000 \\
\hline $\begin{array}{l}\text { Ideal Relation- } \\
\text { ship Rating }\end{array}$ & 25.20 (8.43) & $26.38(5.46)$ & NS & NS \\
\hline
\end{tabular}

buted to the breakup itself as well as to greater breakup distress [7]. In the present study the lacking intimacy items included poor communication, distrust, unreciprocated love, non-caring behavior, diminishing empathy, arguments, infidelity and hypersensitivity.

Surprisingly, the affiliation, sexuality and autonomy items did not differentiate the high from the low breakup distress groups. Affiliation was cited by $44 \%$ of the adolescents in the Connelly and McIsaac study [9] as being the primary reason for romantic breakups, and sexuality was given as the primary reason by $20 \%$ of their sample. The literature, however, appears to be inconsistent about the importance of these reasons for breakup. In another study on adolescents, an age-related decline was noted on the focus on sexual and affiliative dimensions of relationships in favor of focusing more on intimacy factors [10]. In contrast, at least one other investigator has noted that sexual dissatisfaction, boredom with the relationship and a lack of reciprocated love were important causes of the termination of relationships [15]. In addition, autonomy problems including partner dissimilarity and different work styles were also explanations in that study [15] and in another study [6].

Potential confounding variables differentiated the high distress from the low distress group including the Relationship rating and the Missing the Partner rating. These findings are consistent with previous research reporting greater emotional distress following break-ups of closer relationships [4] and relationships with "greater levels of love" [5].

It was not surprising that the Ideal Relationship Rating scale did not differentiate the groups. Whether the students had high or low breakup distress scores, their ratings of ideal relationships were similar.

One of the expected findings was that a significantly greater number of women than men were in the high distress group. This finding is consistent with earlier studies $[3,16]$. Women are notably more reactive to interpersonal stress and more likely to become depressed following an interpersonal stressor [17]. As those authors suggested, women possibly place more importance on harmonious relationships [18]. Women are also twice as likely as men to be depressed [19]. Those authors noted that this difference might be related to different cognitive styles and greater chronic stress in women [20].

In summary, although this study was focused on replicating a high school student study on romantic breakups but with university students and using a scale instead of an open-ended questionnaire, and quantitative rather than qualitative methods, the only factor on the Breakup Reasons Scale that differentiated high from low breakup distress groups was the intimacy factor. But, as was seen, other variables also differentiated high and low breakup distress groups including the relationship ratings and missing the person ratings, feelings that may have de- 
rived from the breakup rather than contributing to the breakup.

Larger samples are needed to study multiple variables, not just self-report measures, and to conduct regression and structural equations analyses to determine the relative contribution of these variables to breakup reasons and breakup distress and their relationships to each other. In addition, positive effects such as breakup distress-related growth $[1,21]$ need further study. Finally, research on partners' interactions prior to the breakup could reveal the qualities that were critical to the relationship, qualities such as intimacy that disappeared and led to the breakup and the breakup distress.

\section{Acknowledgements}

We thank the students who participated in this study and the research associates who assisted us. Correspondence and requests for reprints should be sent to Tiffany Field, Ph.D., Touch Research Institute, University of Miami School of Medicine, PO Box 016820, Miami, Florida, 33101. Business phone number (305) 243-6781.

\section{REFERENCES}

[1] T. Y. Tashiro and P. Frazier, “'I'll Never be in a Relationship like that again': Personal Growth Following Romantic Relationship Breakups,” Personal Relationships, Vol. 10, No. 1, 2003, pp. 113-128.

[2] P. A. Boelen and A. Reijntjes, "Negative Cognitions in Emotional Problems Following Romantic Relationship Break-Ups,” Stress and Health, Vol. 25, No. 1, 2009, pp. 11-19.

[3] T. Field, M. Diego, M. Pelaez, O. Deeds and J. Delgado, "Breakup Distress in University Students," Adolescence, Vol. 44, No. 176, 2009, pp. 705-727.

[4] J. A. Simpson, "The Dissolution of Romantic Relationships: Factors Involved in Relationship Stability and Emotional Distress,” Journal of Personality and Social Psychology, Vol. 53, No. 4, 1987, pp. 683-692.

[5] D. A. Sbarra, "Predicting the Onset of Emotional Recovery Following Nonmarital Relationship Dissolution: Survival Analyses of Sadness and Anger,” Personality and Social Psychology Bulletin, Vol. 32, No. 3, 2006, pp. 298-312.

[6] C. T. Hill, Z. Rubin and L. A. Peplau, "Breakups before Marriage: The End of 103 Affairs,” Journal of Social Issues, Vol. 32, No. 1, 1976, pp. 147-168.

[7] R. A. Barry, E. Lawrence and A. Langer, "Conceptualization and Assessment of Disengagement in Romantic Relationships,” Personal Relationships, Vol. 15, No. 3, 2008, pp. 297-315.

[8] W. A. Collins, "More than Myth: The Developmental Significance of Romantic Relationships during Adolescence," Journal of Research on Adolescence, Vol. 13, No. 1, 2003, pp. 1-24.
[9] J. Connelly and C. McIsaac, “Adolescents' Explanations for Romantic Dissolutions: A Developmental Perspective,” Journal of Adolescence, Vol. 32, No. 5, 2009, pp. 1209-1223.

[10] S. Shulman and M. Scharf, "Adolescent Romantic Behaviours and Perceptions: Age- and Gender-Related Differences and Links with Family and Peer Relationships," Journal of Research on Adolescence, Vol. 10, No. 1, 2000, pp. 99-118.

[11] A. R. Lieblich, R. Tuval-Mashiach and T. Zibler, "Narrative Research: Reading, Analysis and Interpretation,” Applied Social Research Methods, Sage Publications, Thousand Oaks, Vol. 47, 1998, pp. 1-200.

[12] H. G. Prigerson, P. K. Maciejewski, C. F. Reynolds III, A. J. Bierhals, J. T. Newsom and A. Fasiczka, "The Inventory of Complicated Grief: A Scale to Measure Certain Maladaptive Symptoms of Loss," Psychiatry Research, Vol. 59, No. 1-2, 1995, pp. 65-79.

[13] W. A. Collins and A. Sroufe, "Capacity for Intimate Relationships: A Developmental Construction,” In: W. Furman, B. Brown and C. Feiring, Ed., The Development of Romantic Relationships in Adolescence, Cambridge University Press, Cambridge, 1999, pp. 125-147.

[14] J. Connelly and A. Goldberg, "Romantic Relationships in Adolescence: The Role of Friends and Peers in their Emergence and Development,” In: W. Furman, B. Brown and C. Feiring, Ed., The Development of Romantic Relationships in Adolescence, Cambridge University Press, Cambridge, 1999, pp. 266-290.

[15] S. Sprecher, "Two Sides to the Breakup of Dating Relationships,” Personal Relationships, Vol. 1, No. 3, 1994, pp. 199-222.

[16] C. Perilloux and D. M. Buss, "Breaking up Romantic Relationships: Costs Experienced and Coping Strategies Deployed,” Evolutionary Psychology, Vol. 6, No. 1, 2008, pp. 164-181.

[17] K. D. Rudolph and C. S. Conley, "The Socioemotional Costs and Benefits of Social-Evaluative Concerns: Do Girls Care Too Much,” Journal of Personality, Vol. 73, No. 1, 2005, pp. 115-138.

[18] K. D. Rudolph, "Gender Differences in Emotional Responses to Interpersonal Stress during Adolescence,” Journal of Adolescent Health, Vol. 30, No. S4, 2002, pp. 3-13.

[19] S. Nolen-Hoeksema and J. S. Girgus, "The Emergence of Gender Differences in Depression during Adolescence,” Psychological Bulletin, Vol. 115, No. 3, 1994, pp. 424443.

[20] S. Nolen-Hoeksema, C. Grayson and J. Larson, "Explaining the Gender Differences in Depressive Symptoms," Journal of Personality and Social Psychology, Vol. 77, No. 5, 1999, pp. 1061-1072.

[21] S. Herbert and N. Popadiuk, "University Students' Experiences of Nonmarital Breakups: A Grounded Theory,” Journal of College Student Development, Vol. 49, No. 1, 2008, pp. 1-14. 